\title{
Brain stimulation in attention deficits after traumatic brain injury: a literature review and feasibility study
}

Ėve Boissonnault 1,2,3* $\mathbb{D}$, Johanne Higgins ${ }^{2,3,4}$, Geneviève LaGarde ${ }^{2,3}$, Dorothy Barthélemy ${ }^{2,3,4}$, Céline Lamarre ${ }^{1,2,3}$ and Jehane H. Dagher ${ }^{1,2,3}$

\begin{abstract}
Background: After a traumatic brain injury, disturbances in the attentional processes have a direct negative effect on functional recovery and on return to complex activities. To date, there is no good attention remediation treatment available. The primary objective of this review and pilot study is to provide an overview of the research evidence and to evaluate the feasibility of implementing a tDCS protocol to improve attention disorders in patients with mild complicated to severe subacute TBI, hospitalized in an inpatient rehabilitation facility. Our secondary objective is to extract preliminary data and observational information on participants' response to treatment.

Methods: Participants were recruited from a consecutive series of patients admitted to the TBI unit of a subspecialized regional rehabilitation center. They received a 20-min tDCS stimulation 3 times a week for 3 weeks. A neuropsychological evaluation was performed before and after the intervention. We collected participants' sociodemographic and clinical characteristics as well as information about satisfaction, tolerability, and adverse effects.
\end{abstract}

Results: One hundred sixty-four patients were admitted between September 2018 and January 2020. One hundred fifty-eight were excluded, and 6 patients with presumed attentional deficits were enrolled. None completed the protocol as intended. No major side effects occurred.

Conclusion: Non-invasive brain neurostimulation is promising to enhance attention deficits in patients with TBI. Implementation of a tDCS protocol to fulfill this purpose in an intensive inpatient rehabilitation center has its limitations. We made recommendations to facilitate the implementation of similar projects in the future.

Trial registration: ISRCTN, ISRCTN55243064. Registered 14 October 2020-retrospectively registered.

Keywords: Attention, Brain injuries, Traumatic, Rehabilitation, Transcranial direct current stimulation, Transcranial magnetic stimulation

\footnotetext{
* Correspondence: eve.boissonnault@umontreal.ca

${ }^{1}$ Physical Medicine and Rehabilitation Service, Université de Montréal, Montreal, QC, Canada

${ }^{2}$ Institut universitaire sur la réadaptation en déficience physique de Montréal

(IURDPM), 6300, avenue de Darlington (Pavillon Gingras), Montréal, QC H3S

2J4, Canada

Full list of author information is available at the end of the article
}

(c) The Author(s). 2021 Open Access This article is licensed under a Creative Commons Attribution 4.0 International License, which permits use, sharing, adaptation, distribution and reproduction in any medium or format, as long as you give appropriate credit to the original author(s) and the source, provide a link to the Creative Commons licence, and indicate if changes were made. The images or other third party material in this article are included in the article's Creative Commons licence, unless indicated otherwise in a credit line to the material. If material is not included in the article's Creative Commons licence and your intended use is not permitted by statutory regulation or exceeds the permitted use, you will need to obtain permission directly from the copyright holder. To view a copy of this licence, visit http://creativecommons.org/licenses/by/4.0/. The Creative Commons Public Domain Dedication waiver (http://creativecommons.org/publicdomain/zero/1.0/) applies to the data made available in this article, unless otherwise stated in a credit line to the data. 


\section{Key messages regarding feasibility}

- NIBS is promising for the treatment of attention deficits in persons with TBI undergoing inpatient rehabilitation.

- Complexity of organizing tDCS sessions within inpatient rehabilitation schedule needs careful consideration.

- Recommendations include the assignment of a dedicated research coordinator, completion of the study in an outpatient setting, and a maximum of 2 NIBS sessions per week.

\section{Background}

In the USA, annually, over 20,000 adults receive inpatient rehabilitation for moderate-to-severe traumatic brain injury (TBI) [1]. Studies show that only $26.1 \%$ of individuals with a moderate-to-severe TBI reach a disabilityfree global level of functioning at 5 years post-injury [1]. With regard to cognitive function, $49.1 \%$ of patients with TBI are not fully independent after 5 years [1].

In the acute stage of $\mathrm{TBI}$, the primary injury refers to lesions related to the trauma mechanism [2-4]. Among focal insults, contusion is the commonest and most often located in the frontal and temporal lobes where the fragile brain tissue comes in contact with irregular bony protuberances of the anterior and middle cranial fossa $[2,4,5]$. The secondary injury occurs up to several weeks after the primary injury and can result from excitotoxicity, cerebral edema, ischemia, and neuroinflammation $[4,6]$. Then, functional cell plasticity and remyelination prevail within the first 3 months after insult. Therefore, we can expect the greatest recovery in the subacute phase $[4,6]$. In the acute stage of TBI, impaired consciousness and post-traumatic amnesia are mostly seen, whereas attentional deficits, memory impairments, communication disorders, altered processing speed, and executive dysfunction are noted in the subacute period [5].

Attention is a complex mental activity that refers to how individuals receive and process internal and external stimuli [7]. Sustained attention is the capacity to maintain a constant focus on a continuous and repetitive activity, divided attention is the ability to pay attention and to process information coming from two or more sources, and selective attention is the faculty to maintain focus on one trigger or idea for a short moment without being distracted by environmental or competitive stimuli $[8,9]$. Those disturbances in the attentional processes have a direct negative effect on functional recovery and on return to complex activities after TBI [5]. Thus, attentional impairments represent an important target in the rehabilitation intervention in subacute phases of TBI. Traditional attention remediation programs consisting of a battery of pen and paper tasks, informatics software, and coping strategies have shown their usefulness, but the evidences supporting specific intervention strategies remains limited [10].

\section{Transcranial neurostimulation}

To influence neuronal plasticity, non-invasive brain neurostimulation (NIBS) uses an extrinsic-induced electrical stimulus to modulate neuronal excitability, synaptic strength, and dendritic connections. Long-term potentiation (LTP) increases synaptic transmission between two neurons by modulating gamma-aminobutyric acid (GABA)ergic and glutamatergic synapses, while longterm depression (LTD) decreases it and reduces glutamate excitotoxicity and GABA-mediated inhibition $[4,11$, 12]. The two most studied modalities are transcranial direct current stimulation (tDCS) and repetitive transcranial magnetic stimulation (rTMS). Transcranial direct current stimulation allows a weak direct current to flow from the anode to the cathode placed on the scalp to modify the resting membrane potential and modulate the activity level of spontaneous excitatory neurons. Anodal tDCS increases the excitability of the cortex, and cathodal stimulation decreases it. rTMS generates a magnetic field that induces an electric current to neural tissue. Highfrequency stimulation facilitates neuronal efficiency, while low-frequency rTMS reduces it $[3,12]$. Depending on the frequency of repetitive transcranial magnetic stimulation (rTMS) or the polarity of the tDCS, these techniques can induce LTP-like or LTD-like effects that last beyond the stimulation time frame $[3,4,11,12]$.

For this research project, tDCS was determined a better option than rTMS. First, its convenience such as portability allows a better adherence to treatment. Furthermore, the current produced by tDCS being less focal than the rTMS is of interest given the diffuse nature of the TBI. Lastly, tDCS has not been reported to induce seizures and thus appears to be a safer choice $[3,13,14]$.

\section{Neurostimulation and cognitive impairment}

To date, studies have mainly explored the use of neurostimulation to improve psychiatric disorders, stroke rehabilitation, and healthy subjects $[3,12,13]$. Among those, Dubreuil-Vall et al. concluded that stimulating the left dorsolateral prefrontal cortex (DLPFC) leads to a significant improvement in reaction time [15], and Jones et al. demonstrated a significant improvement on the working memory task with stimulation of the right frontoparietal area [16].

Research on patients with TBI has been pursued only recently because NIBS and especially rTMS are regarded as relative contraindications given that TBI increases neuronal excitability and seizure risk [13]. Posttraumatic epilepsy has an incidence of about $5 \%$ in 
patients with closed head injuries and 50\% in those with a penetrating injury [3]. Seizures are the most concerning adverse events in the therapeutic application of NIBS. If compensatory safety steps are taken, experts agree that the expected benefit justifies the increased risk $[3,13]$. In fact, literature reports only two incidences of seizures in patients with TBI, both in studies using rTMS and none in studies using tDCS [13].

Two systematic reviews highlight the use of NIBS for improvement of motor function, memory, tinnitus, alteration of consciousness, and depression $[11,13]$. The most recent concluded that tDCS is a safe and non-invasive neuromodulatory technique that may be best combined with other therapeutics to improve cognitive and motor outcomes [11]. Out of the 14 studies reviewed, seven used tDCS to improve responsiveness in patients with disorders of consciousness, six in cognition and one in motor outcomes. They underline the challenge in conducting clinical trials due to the heterogeneous rehabilitation interventions and the difficulty in targeting a cognitive function as it does not correspond to a delineated network as compared to motor function [11].

Only eight papers were published on the impact of NIBS on attention after TBI with abnormal structural imaging in human subjects [7, 17-23]. Four research teams used rTMS [17-19, 23], and four used tDCS [7, 20-22]. Five of the protocols targeted the DLPFC [7, 20-23], four of which chose the left side [7, 21-23]. Because of the studies' low statistical power, wide variability in type of attention evaluated, study design, and lack of consistency between attention type and the tests chosen to assess it, it was difficult to draw a conclusion on NIBS' effectiveness. Nonetheless, the majority of results were promising and exhibit a positive trend, except for one pilot study [21] and one randomized doubleblind trial [23] which failed to show significant differences between the groups. Four studies showed an improvement in some form of attention [17-20], two studies showed an improvement in reaction time [7, 20], one study reported gains in activities of daily living [18], and three studies revealed favorable visible changes in brain imaging (magnetic resonance imaging (MRI), functional MRI, photon emission computed tomography (SPECT) scans) $[17,18,20]$. Ulam et al.'s study is the only one with all 26 patients studied in the subacute phase (the first 6 months following trauma). It showed significant electroencephalogram (EEG) changes after 10 consecutive sessions of tDCS compared to the sham group, suggesting improved regulation of cortical excitability that correlates with improved performance on neuropsychological tests [22]. A study by Kang et al., which also included subacute patients with TBI, demonstrated that a single session of anodal tDCS applied to the left dorsolateral prefrontal cortex (DLPFC) improved attention compared to the sham stimulation, suggesting its potential role in improving attention [7]. This finding is consistent with literature reporting the crucial role that DLPFC plays on attention [5, 20,22].

In accordance with theory and previous studies, we hypothesized that anodal tDCS applied on the left DLPFC has the potential to enhance attention in patients with mild complicated to severe TBI. Although TBI causes multiple cognitive impairments, we targeted specifically the attentional deficit because of its impact on rehabilitation.

The primary objective of this pilot study was to evaluate the feasibility of implementing an intervention protocol consisting of nine sessions of tDCS to improve attention disorders in patients with mild complicated to severe subacute TBI hospitalized in a rehabilitation facility. Our secondary objective was to extract preliminary data and observational information on participant responses to treatment on selective attention.

\section{Methods \\ Participants}

Participants were recruited from a consecutive series of patients admitted to a functional rehabilitation TBI unit at the Institut universitaire sur la réadaptation en déficience physique de Montréal (IURDPM), a subspecialized regional rehabilitation center in Montreal, Canada. Eligible patients were approached by a physician or nurse external to the research team, and written informed consent was obtained from all participants. We arbitrarily agreed that five subjects would be sufficient to test the feasibility of our protocol.

Inclusion criteria were (1) current hospitalization; (2) age 18 years old or more; (3) diagnosis of mild complicated, moderate, or severe TBI [24]; (4) attentional impairment as per qualitative clinical assessment; (5) French or English speaking; (6) tolerance to 45 to $60 \mathrm{~min}$ neuropsychology evaluation; and (7) capacity to consent in accordance with the Nova Scotia Hospitals Act [25].

Exclusion criteria were (1) history of neurological disease not resulting from the current TBI (e.g., stroke, multiple sclerosis, neurodegenerative disorders), (2) psychiatric illness (e.g., depression, schizophrenia, anxiety disorders), (3) aphasia and compromises in understanding instructions, (4) significant deafness or blindness, (5) contraindication to tDCS (e.g., seizure, extensive cranial vault lesion, pregnancy or breastfeeding, pacemaker, cochlear implants, or cerebral metal implanted device or clip), (6) scar or skull deformity at the site of electrode placement, (7) epileptogenic medication, and (8) penetrating TBI.

\section{Study design}

This study was designed for patients to receive stimulation over a period of 4 weeks, as presented in Table 1 . 
Table 1 Study design

\begin{tabular}{|c|c|c|c|}
\hline T0 & T1 & $\begin{array}{lllllll}\text { T2 } & \text { T3 } & \text { T4 } & \text { T5 } & \text { T6 } & \text { T7 } & \text { T8 }\end{array}$ & T9 \\
\hline 1 week or less & \multicolumn{3}{|c|}{$3 \times /$ week $\times 3$ for a total of 9 tDCS active stimulation sessions } \\
\hline $\begin{array}{l}\text { Sociodemographic questionnaire, TEA (EC, ECD), } \\
\text { Ruff 2\&7, CPT-3, D-KEFS (Stroop), WAIS-IV (DS, CD, } \\
\text { BD) }\end{array}$ & $\begin{array}{l}\text { First } \\
\text { stimulation } \\
\text { session }\end{array}$ & Adverse effects questionnaire & $\begin{array}{l}\text { Satisfaction and tolerability questionnaire, TEA (EC, } \\
\text { ECD), Ruff 2\&7, CPT-3, D-KEFS (Stroop), WAIS-IV (DS, } \\
\text { CD, BD) }\end{array}$ \\
\hline
\end{tabular}

Abbreviations: TEA Test of Everyday Attention, EC elevator counting, ECD elevator counting with distraction, CPT-3 Conners' Continuous Performance Test 3rd Edition, D-KEFS Delis-Kaplan Executive Function System, WAIS-IV Wechsler Adult Intelligence Scale-fourth edition, DS Digit Span, CD Coding, BD Block Design

Sociodemographic information was collected on patients' sex, age, ethnicity, and education from patients' interviews and medical records.

All subjects underwent a neuropsychological evaluation (T0). Subjects were intended to start the tDCS protocol, which consisted of 20-min tDCS active stimulation 3 times a week for 3 weeks for a total of 9 sessions (T1-T9). Customized questionnaires to evaluate satisfaction (Table 3), tolerability, and adverse effects (Table 4) as well as a post-treatment neuropsychological evaluation were administered after the last session (T9). In between stimulation sessions, participants pursued their regular functional intensive rehabilitation.

\section{Transcranial direct current stimulation}

The tDCS was applied by experienced researchers. Skin at the site of the electrodes was cleansed with alcohol. Two saline-soaked electrodes of $25 \mathrm{~cm}^{2}$ each $(5 \times 5 \mathrm{~cm})$ were placed on the scalp: an anode (excitatory electrode) overlying the left DLPFC, and a cathode (reference electrode) above the right supraorbital area (respectively location F5 and F2p, according to the 10-10 electroencephalography system for electrode placement) [26]. The electrodes were inserted into $5 \times 5$-cm sponges soaked in saline and fixed with two elastic bands, and tDCS was delivered using a battery-driven tDCS stimulator (Model 1300A; Soterix Medical, New York, NY). Current delivery was monitored throughout the testing. Patients underwent 20-min sessions of tDCS at an intensity of $2 \mathrm{~mA}$ and a current density of $0.08 \mathrm{~mA} / \mathrm{cm}^{2}$. Those parameters were considered safe [14]. Subjects, seated in a quiet room during stimulation, were asked to remain inactive. Participants' tolerance to the stimulation, satisfaction, tolerability, and adverse effects were recorded at the end of the procedure.

\section{Outcome measures}

\section{Primary outcome}

To assess the protocol's feasibility, we collected data on recruitment, refusal, retention, and therapeutic compliance rate. We registered the number of, and reasons for, withdrawals. To monitor tolerance, adverse effects, and safety, each subject was invited to fill out a customized questionnaire (Table 4) adapted from those provided by Brunoni et al. [14].

\section{Secondary outcome}

We hypothesized that selective attention should improve with $\mathrm{tDCS}$. Specific tests were administered before and after stimulation. The evaluation is routinely given by IURDPM's neuropsychologists and takes between 45 and $60 \mathrm{~min}$ in total to complete. All tests were administered by an experienced neuropsychologist. All tests used have a good test-retest reliability and validity for subjects with TBI [9, 27-30].

Main measures used were: the Test of Everyday Attention (TEA), sensitive to test selective attention [9]; the Ruff 2 E 7 Selective Attention Test, a measure of sustained and selective attention [8]; the Conners' Continuous Performance Test 3rd Edition (CPT-3), for visual sustained attention, vigilance, impulsivity, and inattentiveness [31]. Secondary measures related to attention used were the Stroop from the Delis-Kaplan Executive Function System (D-KEFS) for selective attention [32] and the Digit Span and Coding subtests from the Wechsler Adult Intelligence Scale-fourth edition (WAIS-IV) respectively assess working memory and processing speed [33, 34]. Secondary measures not related to attention were the Block Design subtest from the WAIS-IV that evaluates the ability to analyze and synthesize abstract visual stimuli. The results were used to measure the specificity of our stimulation intervention. It is therefore not expected to improve compared with measures related to attention $[33,34]$.

\section{Results}

A total of 164 patients were admitted to the TBI unit at the IURDPM for intensive rehabilitation between September 2018 and January 2020; all were identified for this research project. From this group, 158 subjects were excluded (Fig. 1). The remaining six patients (five males and one female) with presumed attentional deficit related to TBI were recruited to receive the tDCS intervention (Fig. 2). Recruitment ended after we reached our arbitrary objective of five participants. Sociodemographic and clinical characteristics of participants are presented in Table 2.

Participants received an average of $4.2 \pm 3.4$ stimulation sessions, representing $46.3 \%$ of the target number of interventions. None of the subjects went through the full planned nine-session protocol. Two subjects completed eight sessions, while one did not undergo any because of 


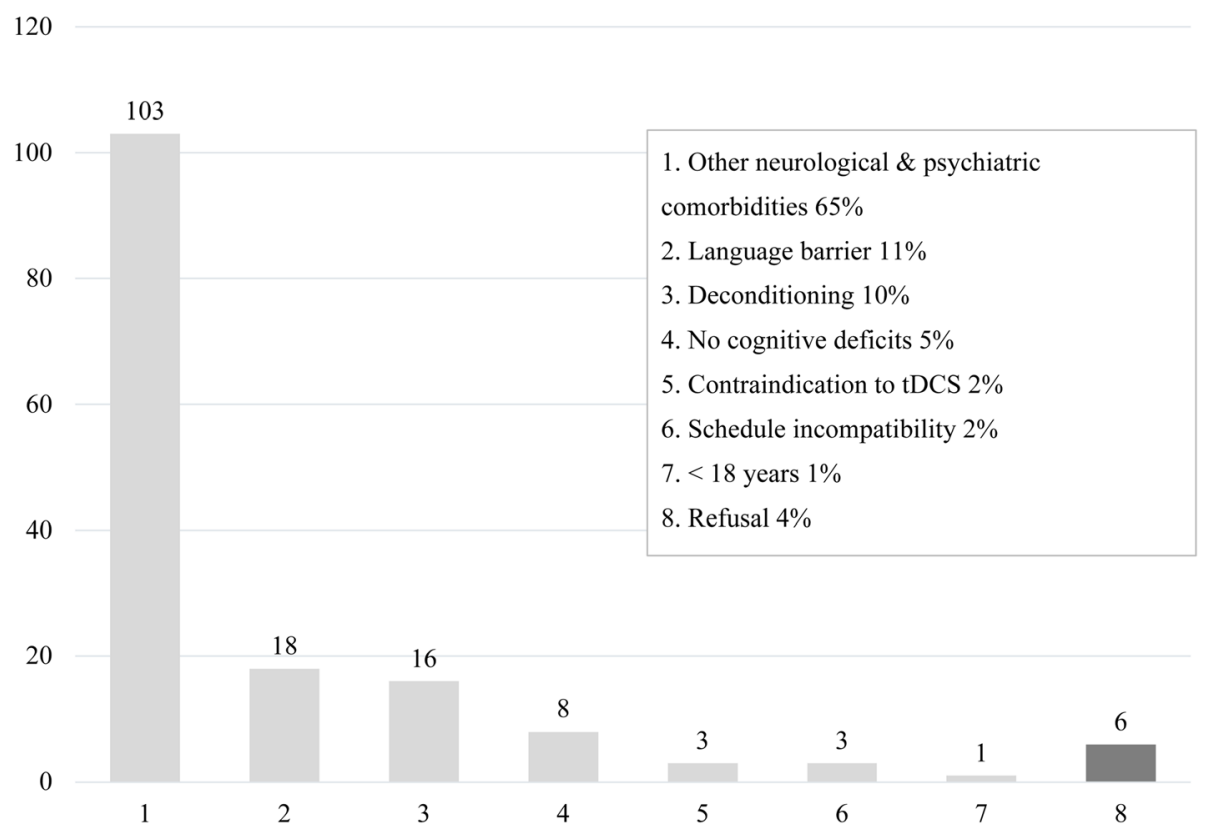

Fig. 1 Exclusions and refusals

scheduling incompatibility. It took an average of $3.5 \pm$ 1.3 weeks between admission and the first assessment, $3.1 \pm 1.8$ weeks between the first and the last assessment, for a total of $7.1 \pm 2.8$ weeks between the admission and the last evaluation, as opposed to the 4-week initial design plan.

Three patients completed the satisfaction questionnaire; all felt overall somewhat or very satisfied with their participation and would possibly or certainly recommend the project to someone else (Table 3).

Throughout the 25 completed tDCS sessions, 4 participants reported tingling, 3 skin redness, and 1 burning sensation. The effects were minor and temporary. One patient withdrew from the study due to intense headaches and fatigue following the stimulation and attributed it to tDCS (Table 4).

All six patients completed the initial neuropsychological assessment (T0). Four patients completed neuropsychological assessments after stimulation. Despite prior clinical evaluation by physicians specialized in TBI, specific attention deficits were absent in four of the six subjects formally evaluated. In one patient, due to early hospital discharge, the final assessment was done at 1 week and after two neurostimulation sessions (T2). The remaining subject completed eight tDCS sessions and had attention impairment objectified, but no clinically significant change was seen at T8.

\section{Discussion}

Satisfaction did not seem to be an obstacle to our intervention. The high rate of attrition before completion of nine sessions testifies to the complexity of organization of three sessions per week for 3 weeks with a simultaneous complete inpatient rehabilitation schedule. None of the participants received the intended nine intervention sessions and, in all subjects, stimulation sessions took longer than the originally scheduled 4 weeks. On this basis, we propose to reduce the number of weekly stimulation sessions.

Despite prior clinical evaluation by physicians specialized in TBI, specific attentional deficits were absent in four subjects as per the first neuropsychological evaluation. In retrospect, the inclusion should begin after the first neuropsychology evaluation. Considering the small size of our final sample, neuropsychological data were not used for a formal analysis but for feasibility assessment. With this in mind, the feasibility and tolerability of neuropsychological testing are adequate.

Challenges relating to subjects' recruitment were the reluctant interest for neurostimulation which seems invasive and time consuming. An important finding is the exclusion of many potential participants. The exclusion criteria were determined according to previous studies. Published contraindications of tDCS are very restrictive, and as such, many patients did not meet the inclusion criteria (67\% of subjects). Neurologic and psychiatric comorbidities, epilepsy, and substance abuse are common comorbidities in patients with TBI and hence restrict study inclusion.

The absence of a dedicated coordinator influenced adherence to the study protocol and communication between subjects, clinicians, and the research team. 


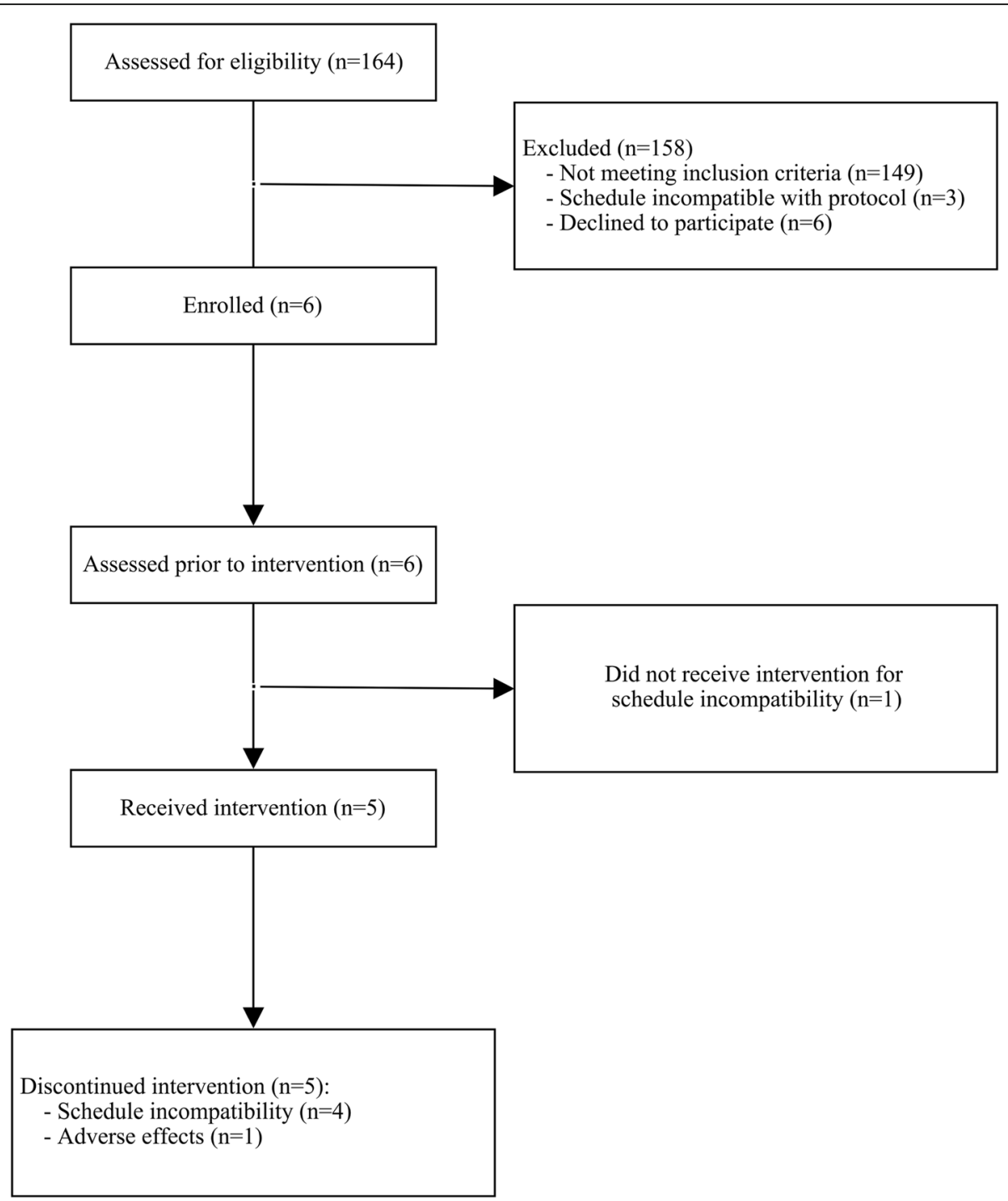

Fig. 2 Study flow diagram

Table 2 Patients' characteristics

\begin{tabular}{|c|c|c|c|c|c|c|c|c|c|}
\hline Patient & $\begin{array}{l}\text { Sex/age } \\
\text { (years) }\end{array}$ & $\begin{array}{l}\text { Ethnic } \\
\text { group }\end{array}$ & $\begin{array}{l}\text { Education } \\
\text { (years) }\end{array}$ & $\begin{array}{l}\text { Time since TBI at T0 } \\
\text { (weeks) }\end{array}$ & $\begin{array}{l}\text { Severity/initial } \\
\text { GCS }\end{array}$ & $\begin{array}{l}\text { Cause of } \\
\text { injury }\end{array}$ & Brain lesion (location) & Fracture & Surgery \\
\hline 1 & $\mathrm{M} / 70$ & $\begin{array}{l}\text { White } \\
\text { Canadian }\end{array}$ & 16 & 11 & Mod/15 & Fall & $\begin{array}{l}\text { SAH, SDH (R, L), contusion (RF, LF, } \\
\text { LT, RT) }\end{array}$ & $\mathrm{Nil}$ & $\mathrm{Nil}$ \\
\hline 2 & $M / 51$ & Black African & 13 & 17.9 & Mod/14 & MVC & $\mathrm{SDH}(\mathrm{L})$ & $\mathrm{Nil}$ & Burr hole \\
\hline 3 & $F / 74$ & $\begin{array}{l}\text { White } \\
\text { Canadian }\end{array}$ & 9 & 6.4 & $M C / 13$ & MVC & SAH, SDH (L), contusion (LF) & Nil & Nil \\
\hline 4 & $\mathrm{M} / 53$ & $\begin{array}{l}\text { White } \\
\text { Canadian }\end{array}$ & 9 & 15.3 & $\mathrm{~S} / 3$ & Fall & Contusion (LF, LT, O), DAl & Face & $\mathrm{Nil}$ \\
\hline 5 & $M / 49$ & $\begin{array}{l}\text { White } \\
\text { Canadian }\end{array}$ & 15 & 9.6 & $S / 3$ & Fall & SAH, SDH (R), contusion (RF, RT) & $\begin{array}{l}\text { Face, LP, } \\
\text { LT }\end{array}$ & Nil \\
\hline 6 & $M / 53$ & $\begin{array}{l}\text { White } \\
\text { Canadian }\end{array}$ & 12 & 9.9 & $S / 6$ & Assault & SAH (LF), SDH (L), EDH (RT) & Face, RT & Craniectomy \\
\hline $\mathrm{m} \pm \mathrm{SD}$ & $58.3 \pm 10.8$ & N/A & $12.3 \pm 2.9$ & $11.7 \pm 4.2$ & N/A & N/A & N/A & N/A & N/A \\
\hline
\end{tabular}


Table 3 Satisfaction

\begin{tabular}{|c|c|c|c|c|c|c|c|c|}
\hline Patients & $\begin{array}{l}\text { Number of } \\
\text { completed tDCS } \\
\text { sessions }\end{array}$ & $\begin{array}{l}\text { Satisfaction } \\
\text { with } \\
\text { information }\end{array}$ & $\begin{array}{l}\text { Satisfaction } \\
\text { with } \\
\text { organization }\end{array}$ & $\begin{array}{l}\text { Conflict with } \\
\text { rehabilitation } \\
\text { schedule }\end{array}$ & $\begin{array}{l}\text { Course of the } \\
\text { stimulation } \\
\text { sessions }\end{array}$ & $\begin{array}{l}\text { Course } \\
\text { assessment } \\
\text { sessions }\end{array}$ & $\begin{array}{l}\text { Overall } \\
\text { satisfaction }\end{array}$ & $\begin{array}{l}\text { Recommend } \\
\text { to someone } \\
\text { else }\end{array}$ \\
\hline 1 & 8 & $\begin{array}{l}\text { Somewhat } \\
\text { satisfied }\end{array}$ & $\begin{array}{l}\text { Somewhat } \\
\text { satisfied }\end{array}$ & Never & $\begin{array}{l}\text { Somewhat } \\
\text { satisfied }\end{array}$ & $\begin{array}{l}\text { Somewhat } \\
\text { satisfied }\end{array}$ & $\begin{array}{l}\text { Somewhat } \\
\text { satisfied }\end{array}$ & Possibly \\
\hline 2 & 2 & - & - & - & - & - & - & - \\
\hline 3 & 0 & - & - & - & - & - & - & - \\
\hline 4 & 8 & Very satisfied & Very satisfied & Never & Very satisfied & Very satisfied & $\begin{array}{l}\text { Very } \\
\text { satisfied }\end{array}$ & Certainly \\
\hline 5 & 5 & Very satisfied & Very satisfied & Never & Very satisfied & Very satisfied & $\begin{array}{l}\text { Very } \\
\text { satisfied }\end{array}$ & Certainly \\
\hline 6 & 2 & - & - & - & - & - & - & - \\
\hline
\end{tabular}

Second, our intensive functional rehabilitation setting is characterized by a short length of stay, medically active patients, and a relatively busy rehab schedule hindering participation. Moreover, because of memory impairment and dysexecutive functioning, it is challenging for patients with TBI to follow a schedule, and in order to promote social reintegration, patients are encouraged to leave their room during free time. Therefore, it was often difficult for the research team to schedule subjects, lengthening the recruitment and stimulation design. In addition, no designated neuropsychologist and no neuropsychology evaluation schedules were implemented, which also contributed to the delay between admission and first evaluation. When the neuropsychologist had both the clinical and research role, an ethical conflict was palpable in treating the patient and maintaining their objectivity in administering the chosen design tests. A single external neuropsychologist could ensure a homogenous administration and analysis of tests.

This feasibility study sheds light on the logistic and technical implication of neurostimulation. First, it allows professionals to discover this new interventional technique, its novel use on the TBI unit, and its promising potential. A series of recommendations are suggested in

Table 4 Adverse effects

\begin{tabular}{llllllll}
\hline Adverse effects/patients & $\mathbf{1}$ & $\mathbf{2}$ & $\mathbf{3}$ & $\mathbf{4}$ & $\mathbf{5}$ & $\mathbf{6}$ & Total effects reported \\
\hline Tingling & $\times$ & & & $\times$ & $\times$ & $\times$ & 4 \\
Skin redness & $\times$ & & & $\times$ & $\times$ & 3 \\
Burning sensation & & $\times$ & & & & 1 \\
Headache & & & & & $\times$ & 1 \\
Fatigue & & & & & $\times$ & 1 \\
Itching & & & & & 0 \\
Scalp pain & & & & & 0 \\
Neck pain & & & & & 0 \\
Sleepiness & & & & & 0 \\
Trouble concentrating & & & & & 0 \\
Acute mood change & & & & & 0 \\
\hline
\end{tabular}

order to facilitate the implementation of similar projects in the future:

(1) Assign an experienced research coordinator to improve recruitment, adherence to the protocol, and communication between subjects, clinicians, and the research team.

(2) Assign an external neuropsychologist to avoid ethical conflict and to allow for efficient testing, scheduling, and analysis

(3) Consider evaluation by a single neuropsychologist to ensure homogeneity of results

(4) Consider stimulation sessions by a single researcher to ensure homogeneity of the intervention and data collection

(5) Enroll subjects after the first neuropsychological assessment to improve screening for the cognitive deficit studied (i.e., attentional deficit)

(6) Complete the study in an outpatient setting if discharge occurs before protocol ends

(7) Plan no more than two NIBS sessions per week to realistically integrate them in a rehab schedule

\section{Conclusions}

We believe that NIBS is a promising method for the treatment of attention deficits in patients with TBI undergoing inpatient rehabilitation. Based on this study and the existing literature, NIBS has its hurdles. Implementation of this newer technique comes with some challenges. Nevertheless, our study could stand as an aide for researchers to investigate the efficacy of neurostimulation in patients with TBI.

\footnotetext{
Abbreviations

TBI: Traumatic brain injury; NIBS: Non-invasive brain neurostimulation; LTP: Long-term potentiation; LTD: Long-term depression; tDCS: Transcranial direct current stimulation; rTMS: Repetitive transcranial magnetic stimulation; DLPFC: Dorsolateral prefrontal cortex; TEA: Test of Everyday Attention; CPT3: Conners' Continuous Performance Test 3rd Edition; D-KEFS: Delis-Kaplan Executive Function System; WAIS-IV: Wechsler Adult Intelligence Scale-fourth edition
} 


\section{Acknowledgements}

Not applicable.

\section{Authors' contributions}

EB is a senior resident in PM\&R at Université de Montréal. She participated in the review of the literature, the creation of the protocol, the analysis of the results, and the production and completion of the manuscript. She is the main contributor to the study. JH and DB are associate professors at the School of Rehabilitation from Université de Montréal and researcher members of the CRIR. They have experience in non-invasive brain stimulation (rTMS and tDCS). They elaborated the tDCS protocol, gave the stimulation, and contributed to the results of the manuscript. GL is a neuropsychologist specialized in TBI at the Neurology program from the IURDPM. She participated in the review of the literature, the creation of the neuropsychology evaluation protocol, the analysis of the neuropsychological assessment results, and the production of the manuscript. CL is a physiatrist specialized in TBI rehabilitation at the IURDPM. She participated in the review of the literature, the creation of the protocol, and proofreading the manuscript. JHD is a physiatrist specialized in TBI rehabilitation at the IURDPM. She participated in the review of the literature, the creation of the protocol, the analysis of the results, and the production and writing of the manuscript. The authors read and approved the final manuscript.

\section{Funding}

This work was supported by the Centre for Interdisciplinary Research in Rehabilitation of Greater Montreal (CRIR) under Grant "New Initiatives".

\section{Availability of data and materials}

The protocol and datasets generated during and/or analyzed during the current study are available from the corresponding author on reasonable request.

\section{Declarations}

\section{Ethics approval and consent to participate}

The study protocol was approved by CRIR Research Ethics Board (CRIR-13370518). Written informed consent to participate was obtained from all participants.

\section{Consent for publication}

Patients signed informed consent regarding publishing their data.

\section{Competing interests}

The authors declare that they have no competing interests.

\section{Author details}

${ }^{1}$ Physical Medicine and Rehabilitation Service, Université de Montréal, Montreal, QC, Canada. ${ }^{2}$ Institut universitaire sur la réadaptation en déficience physique de Montréal (IURDPM), 6300, avenue de Darlington (Pavillon Gingras), Montréal, QC H3S 2J4, Canada. ${ }^{3}$ Centre for Interdisciplinary Research in Rehabilitation of Greater Montreal (CRIR), Montreal, QC, Canada. ${ }^{4}$ School of Rehabilitation, Faculty of Medicine, Université de Montréal, Montreal, QC, Canada.

Received: 14 October 2020 Accepted: 21 May 2021

\section{Published online: 31 May 2021}

\section{References}

1. Department of Health and Human Services; Centers for Disease Control and Prevention; National Center for Injury Prevention and Control: Administration for Community Living (ACL) National Institute on Disability, Independent Living and Rehabilitation Research (NIDILRR): One and five year outcomes after moderate-to-severe traumatic brain injury requiring inpatient rehabilitation: traumatic brain injury report. U.S: Stephen B. Thacker CDC Library collection; 2018.

2. McKee $A C$, Daneshvar DH. The neuropathology of traumatic brain injury. Handb Clin Neurol. 2015;127:45-66. https://doi.org/10.1016/B978-0-444-52 892-6.00004-0

3. Demirtas-Tatlidede A, Vahabzadeh-Hagh AM, Bernabeu M, Tormos JM, Pascual-Leone A. Noninvasive brain stimulation in traumatic brain injury. J
Head Trauma Rehabil. 2012;27(4):274-92. https://doi.org/10.1097/HTR.0b013 e318217df55.

4. Kim WS, Lee K, Kim S, Cho S, Paik NJ. Transcranial direct current stimulation for the treatment of motor impairment following traumatic brain injury. J Neuroeng Rehabil. 2019;16(1):14. https://doi.org/10.1186/s12984-019-0489-9.

5. Rabinowitz AR, Levin HS. Cognitive sequelae of traumatic brain injury. Psychiatr Clin North Am. 2014;37(1):1-11. https://doi.org/10.1016/j.psc.2 013.11.004.

6. Li S, Zaninotto AL, Neville IS, Paiva WS, Nunn D, Fregni F. Clinical utility of brain stimulation modalities following traumatic brain injury: current evidence. Neuropsychiatr Dis Treat. 2015;11:1573-86. https://doi.org/10.214 7/NDT.S65816.

7. Kang EK, Kim DY, Paik NJ. Transcranial direct current stimulation of the left prefrontal cortex improves attention in patients with traumatic brain injury: a pilot study. J Rehabil Med. 2012:44(4):346-50. https://doi.org/10.2340/1 6501977-0947.

8. Ruff R, Allen C. Ruff $2 \& 7$ Selective Attention Test. Stockholm: Psykologiförlaget AB; 1996

9. Robertson $I H$, Ward T, Ridgeway V, Nimmo-Smith I. The Test of Everyday Attention (TEA). Bury St Edmunds: Thames Valley Test Company; 1994.

10. Ponsford J, Bayley M, Wiseman-Hakes C, Togher L, Velikonja D, Mclntyre A, et al. INCOG recommendations for management of cognition following traumatic brain injury, part II: attention and information processing speed. J Head Trauma Rehabil. 2014;29(4):321-37. https://doi.org/10.1097/HTR. 0000000000000072

11. Zaninotto AL, El-Hagrassy MM, Green JR, Babo M, Paglioni VM, Benute GG, et al. Transcranial direct current stimulation (tDCS) effects on traumatic brain injury (TBI) recovery: a systematic review. Dement Neuropsychol. 2019. 13(2):172-9. https://doi.org/10.1590/1980-57642018dn13-020005.

12. Henrich-Noack P, Sergeeva EG, Sabel BA. Non-invasive electrical brain stimulation: from acute to late-stage treatment of central nervous system damage. Neural Regen Res. 2017;12(10):1590-4. https://doi.org/10.4103/1 673-5374.217322.

13. Dhaliwal SK, Meek BP, Modirrousta MM. Non-invasive brain stimulation for the treatment of symptoms following traumatic brain injury. Front Psychiatry. 2015;6:119.

14. Brunoni AR, Amadera J, Berbel B, Volz MS, Rizzerio BG, Fregni F. A systematic review on reporting and assessment of adverse effects associated with transcranial direct current stimulation. Int J Neuropsychopharmacol. 2011;14(8):1133-45. https://doi.org/10.1017/S14 61145710001690.

15. Dubreuil-Vall L, Chau P, Ruffini G, Widge AS, Camprodon JA. tDCS to the left DLPFC modulates cognitive and physiological correlates of executive function in a state-dependent manner. Brain Stimul. 2019;12(6):1456-63. https://doi.org/10.1016/j.brs.2019.06.006.

16. Jones KT, Peterson DJ, Blacker KJ, Berryhill ME. Frontoparietal neurostimulation modulates working memory training benefits and oscillatory synchronization. Brain Res. 2017;1667:28-40.

17. Bonni S, Mastropasqua C, Bozzali M, Caltagirone C, Koch G. Theta burst stimulation improves visuo-spatial attention in a patient with traumatic brain injury. Neurol Sci. 2013;34(11):2053-6. https//doi.org/10.1007/s10072-013-1412-y.

18. Hara T, Abo M, Sasaki N, Yamada N, Niimi M, Kenmoku M, et al. Improvement of higher brain dysfunction after brain injury by repetitive transcranial magnetic stimulation and intensive rehabilitation therapy: case report. Neuroreport. 2017:28(13):800-7. https://doi.org/10.1097/WNR. 0000000000000830

19. Pachalska M, Lukowicz M, Kropotov JD, Herman-Sucharska I, Talar J. Evaluation of differentiated neurotherapy programs for a patient after severe TBI and long term coma using event-related potentials. Med Sci Monit. 2011;17(10):CS120-8. https://doi.org/10.12659/msm.881970.

20. Sacco K, Galetto V, Dimitri D, Geda E, Perotti F, Zettin M, et al. Concomitant use of transcranial direct current stimulation and computer-assisted training for the rehabilitation of attention in traumatic brain injured patients: behavioral and neuroimaging results. Front Behav Neurosci. 2016:10:57.

21. Lesniak M, Polanowska K, Seniow J, Czlonkowska A. Effects of repeated anodal tDCS coupled with cognitive training for patients with severe traumatic brain injury: a pilot randomized controlled trial. J Head Trauma Rehabil. 2014:29(3):E20-9. https://doi.org/10.1097/HTR.0b013e318292a4c2.

22. Ulam F, Shelton C, Richards L, Davis L, Hunter B, Fregni F, et al. Cumulative effects of transcranial direct current stimulation on EEG oscillations and attention/working memory during subacute neurorehabilitation of 
traumatic brain injury. Clin Neurophysiol. 2015;126(3):486-96. https://doi. org/10.1016/j.clinph.2014.05.015.

23. Neville IS, Zaninotto AL, Hayashi CY, Rodrigues PA, Galhardoni R, Ciampi de Andrade $D$, et al. Repetitive TMS does not improve cognition in patients with TBI: a randomized double-blind trial. Neurology. 2019;93(2):e190-9. https://doi.org/10.1212/WNL.00000000000007748.

24. MSSS et SAAQ: Orientations ministérielles pour le traumatisme craniocérébral léger 2005-2010. Québec: Gouvernement du Québec; 2005.

25. Her Majesty the Queen in right of the Province of Nova Scotia: Hospitals Act: chapter 208 of the revised statutes, 1989. Halifax: Province of Nova Scotia; 2016. p. 6-7.

26. Koessler L, Maillard L, Benhadid A, Vignal JP, Felblinger J, Vespignani H, et al. Automated cortical projection of EEG sensors: anatomical correlation via the international 10-10 system. Neuroimage. 2009;46(1):64-72. https://doi.org/1 0.1016/j.neuroimage.2009.02.006

27. Chan RC, Lai MK. Latent structure of the Test of Everyday Attention: convergent evidence from patients with traumatic brain injury. Brain Inj. 2006;20(6):653-9. https://doi.org/10.1080/02699050600676974.

28. Zane KL, Gfeller JD, Roskos PT, Bucholz RD: The clinical utility of the Conners' Continuous Performance Test-II in traumatic brain injury. Arch Clin Neuropsychol 2016;31(8):996-1005.

29. Guise BJ, Thompson MD, Greve KW, Bianchini KJ, West L. Assessment of performance validity in the Stroop Color and Word Test in mild traumatic brain injury patients: a criterion-groups validation design. J Neuropsychol. 2014;8(1):20-33. https://doi.org/10.1111/jnp.12002.

30. Carlozzi NE, Kirsch NL, Kisala PA, Tulsky DS. An examination of the Wechsler Adult Intelligence Scales, Fourth Edition (WAIS-IV) in individuals with complicated mild, moderate and severe traumatic brain injury (TBI). Clin Neuropsychol. 2015;29(1):21-37. https://doi.org/10.1 080/13854046.2015.1005677.

31. Conners CK. Conners Continuous Performance Test 3rd Edition. Toronto: MHS; 2014.

32. Delis DC, Kaplan E, Kramer JH. Delis-Kaplan Executive Function System ${ }^{\oplus}(\mathrm{D}-$ KEFS ): examiner's manual: flexibility of thinking, concept formation, problem solving, planning, creativity, impulse control, inhibition. Toronto: Pearson; 2001

33. Wechsler D. Wechsler Adult Intelligence Scale-fourth edition: Canadian (WAIS-IV). Toronto: Pearson; 2008.

34. Benson N, Hulac DM, Kranzler JH. Independent examination of the Wechsler Adult Intelligence Scale-fourth edition (WAIS-IV): what does the WAIS-IV measure? Psychol Assess. 2010;22(1):121-30. https://doi. org/10.1037/a0017767

\section{Publisher's Note}

Springer Nature remains neutral with regard to jurisdictional claims in published maps and institutional affiliations.

Ready to submit your research? Choose BMC and benefit from:

- fast, convenient online submission

- thorough peer review by experienced researchers in your field

- rapid publication on acceptance

- support for research data, including large and complex data types

- gold Open Access which fosters wider collaboration and increased citations

- maximum visibility for your research: over $100 \mathrm{M}$ website views per year

At BMC, research is always in progress.

Learn more biomedcentral.com/submissions 